\title{
A REVIEW OF THE 1991 E760 RUN
}

\author{
M. Church
}

20 February 1992

\section{Introduction}

The 1991 E760 run was highly successful. This note is an attempt to record some important information regarding Accumulator operation during the run, so that it will be easily accessible for the next E760 run. The topics are not in any particularly relevant order, but are taken mostly from a seminar given by $M$. Church on 2/13/92. Much ramp data resides in the "E760 Ramps Notebook" and much other data resides in E760 logbooks V, VI, VII, and VIII.

\section{Physics Results}

I list here some of the more important physics results.

1) Discovery of the $1 P_{1}$;

2) Measurement of the $\chi_{2} \longrightarrow \gamma \gamma$ branching ratio;

3) Measurement of the $J / \Psi$ and $\Psi^{\prime}$ full widths;

4) Further improvement on the measurement of the $\chi_{2} \longrightarrow \Psi \gamma$ angular distribution functions;

5) Measurement of the $\bar{p} p \longrightarrow e^{+} e^{-}$electromagnetic form factor;

6) Measurement of the $\bar{p} p \longrightarrow \bar{p} p$ elastic scattering parameter, $\rho$.

\section{General Run Summary}

Table 1 summarizes the data collected during the run. Fig. 1 shows the luminosity collected week by week and the average stacking rate per stack. Fig. 2 shows the luminosity integrated through the run. A total of $31 p b^{-1}$ was collected. Fig 3 . shows a typical deceleration (above transition) with a typical efficiency of $95 \%$. Early in the run the efficiency was very close to $100 \%$. I suspect there was an aperture restriction - possibly a momentum aperture limitation as we wandered too close to the edge of the momentum aperture. The deceleration efficiency really should be $100 \%$. Fig. 4 shows a typical data-taking cycle. The break point $2 / 3 \mathrm{rds}$ through the data-taking is a deceleration to the $\eta_{c}$. Fig. $4 \mathrm{a}$ and $4 \mathrm{~b}$ show horizontal and vertical aperture as a function of momentum for the 1990 ramps and 1991 ramps as measured in Jan. 1991. During the run, the actual apertures were known to be smaller. The problem of radiation during stacking was solved during this run by the addition of 
more shielding. Fig. 4c shows the final layout of shielding blocks. A $40 \mathrm{~mA}$ stack gave about 3 mrads of radiation in the $\mathrm{Pb}-\mathrm{G}$ as measured by standard chipmunks. The total amount of radiation received during the run was about $100 \mathrm{rads}$ - bringing the total to about 200 rads for the $\mathrm{Pb}-\mathrm{G}$.

\section{Transition Crossing}

Fig. 5 shows $\gamma_{T}$ as a function of beam momentum. The $\gamma_{T}$ jump is about 1 unit. Above transition, $\eta$ is -.0075 and below transition $\eta$ is .0058 . Fig. 6 shows the transition-crossing efficiency and efficiency below transition. Transition crossing was typically $100 \%$ efficient (as much as $30 \mathrm{~mA}$ was taken across transition), but usually some beam was lost when bunching below transition due to the fact that we were so close to the edge of the momentum aperture there. This is undoubtedly because the quads mis-steer the beam during transition crossing. Below transition some beam was lost due to decreasing bucket area. ARF3 could not reliably hold $3 \mathrm{kV}$ and had to be turned back to $2.8 \mathrm{kV}$ later the run. The beam was cooled at POFTT $=4434$. There was some evidence of beam blowup crossing transition (Fig. 7), but not enough to lose beam out of the machine. Cooling below transition was effective (but slow), and when the beam got too small in $\Delta p / p$ the transverse emittances started to grow uncontrollably. Fig. 8 shows the effect of cooling below transition. For the next run a strong effort should be made to keep the beam centered in the quads so that transition crossing does not distort the orbit so much.

\section{Beam Lifetime}

The beam lifetime was generally very good. Figs. 9 and 10 show Accumulator vacuum plots with gas jet on and off. Fig. 11 shows the effect on the beam lifetime of turning on the gas jet. Depending on the gas jet pressure, lifetimes at the $1 P_{1}$ varied from 65 hours to 100 hours. The beam lifetime can be calculated reasonably accurately from 1st principles. The 4 major contributors to the lifetime are:

1) Hard nuclear scattering in the $H_{2}$ gas jet;

2) Coulomb scattering from the the $H_{2}$ nuclei;

3) Scattering from atomic electrons in the $\mathrm{H}_{2}$ gas jet;

4) Everything else.

Typical parameters are:

$P_{\text {beam }}=6500 \mathrm{Mev} / \mathrm{c}$

$\mathrm{Z}=\mathrm{A}=1$

gas jet density $(\rho)=.5 \times 10^{14}$ atoms $/ \mathrm{cm}^{2}$

$I_{\text {beam }}=30 \mathrm{~mA}$

$\sigma_{T}=68 \mathrm{mb}$ (total cross section)

$L_{0}=9.3 \times 10^{30} \mathrm{~cm}^{-2} \mathrm{sec}^{-1}$ (luminosity)

$d E / d x=4.12 \mathrm{Mev} / \mathrm{g} / \mathrm{cm}^{2}$

The total lifetime is given by

$$
1 / L=1 / L_{\sigma}+1 / L_{c}+1 / L_{d E / d x}+1 / L_{e} .
$$


Since the loss rate for each of these processes is proportional to the number of antiprotons in the ring, the lifetime due to any single process is simply $L_{i}=N_{\bar{p}} / R_{i}$, where $R_{i}$ is the loss rate for that process.

The total cross section for hard scattering is $68 \mathrm{mb}$, therefore for the above parameters

$$
L_{\sigma}=N_{\bar{p}} /\left(L_{0} \sigma_{T}\right)=132 \text { hours. }
$$

As long as the betatron cooling system has adequate power to contain the emittance, then the losses due to coulomb scattering from the $\mathrm{H}_{2}$ nuclei will be dominated by individual large scatters. The probability of such a scatter between $\theta$ and $d \theta$ is given by the Rutherford scattering formula:

$$
P(\theta) d \theta=\frac{52.3 \times 10^{-26} F_{0} Z^{2} \rho_{H 2}}{(\beta p c)^{2}} \frac{d \theta}{\theta^{3}}
$$

For the A50 sector of the Accumulator $\beta=8$ meters and the aperture was typically $6 \pi$, therefore

$$
\theta_{\max }=\sqrt{6 \pi / 8}=.85 m r \text {. }
$$

Integrating eq. 3 from $\theta_{\max }$ to $\infty$ gives a lifetime of $L_{c}=750$ hours.

As with coulomb scattering, as long as the momentum cooling can overcome the average $d E / d x$ loss in the gas jet, then beam losses due to scattering with atomic electrons will be dominated by individual large energy transfer scatters. The number of electrons scattered between kinetic energies $T$ and $d T$ is given by

$$
d N=15.8 \times 10^{-20} \frac{N_{0} Z \rho_{H 2}}{\beta^{2}}\left(1-\frac{\beta^{2} T}{T_{\max }}\right) \frac{d T}{T^{2}}
$$

The largest allowable $T$ is determined by the geometry of the momentum cooling pickups. For the 4-8 Ghz system, about $12 \mathrm{~mm}$ from the center of the pickups the phase of the cooling signal changes sign (private communication from D. McGinnis) and cooling is no longer effective. For a lattice dispersion function of 9 meters, this corresponds to $T=8 \mathrm{Mev}$ at a beam momentum of $6500 \mathrm{Mev} / \mathrm{c}$. Integrating eq. 5 from $8 \mathrm{Mev}$ to $T_{\max }$ gives $L_{d E / d x}=500$ hours.

The remainder of the lifetime is simply the lifetime with the gas jet off. This was typically 500 hours at $6500 \mathrm{Mev} / \mathrm{c}$. Adding up these 4 contributions gives a calculated beam lifetime of 77 hours at $6500 \mathrm{Mev} / \mathrm{c}$. The actual beam lifetime was 65 hours, which is in reasonably good agreement with the calculation. The basic formulas for the above calculations can be found in Rossi, "High Energy Particles".

\section{Orbit Length Measurement}

A detailed discussion of the orbit length measurement is contained in $\mathrm{S}$. Werkema's soon-to-be-released pbarnote. Fig. 12 shows a typical difference orbit compared with the P85 fit. Typical P85 "chisqr" was .6, however during the course of the run this gradually got worse, presumably from a deteriorating BPM system, and was typically 1.6 near the end of the run.

\section{Beam Energy Drift}


Figs. 13 and 14 shows the accumulator magnetic field, LCW temperatures, and tunnel (magnet) temperature as a function of time during a typical data-taking period. When stacking stopped, the debuncher and beamlines were turned off to save power and then the beam was decelerated to the operating point. These actions reduced the power consumption in the tunnel from about $2 \mathrm{MW}$ to about .5MW. The LCW temperature feedback system was not able to handle this, and as a result the temperature changed dramatically in the tunnel - causing the magnetic field to change - probably due to the coefficient of thermal expansion of the magnets. This in turn caused the energy to slowly drift (since the beam was slightly bunched). The 4-8 Ghz momentum cooling system, at the low power levels used, did not keep the beam exactly centered under the pickups, and hence the beam position changed. This is shown in Fig. 15, along with the relevant equations. Drifts of about 2-3 mm over the course of a $1 P_{1}$ point were typical. Typically in the middle of such a data-taking cycle, the beam energy had to be moved by hand to keep it near the original energy point. Total energy drift (without changing by hand) was usually about $400 \mathrm{Mev}$ in the center of mass. It was suspected that the apparent magnetic field change might be due to temperature variations on the magnet shunts, but the magnet with the NMR probe was used with and without a shunt and the apparent field change exhibited no difference. In addition, it was suspected that the beam pipe (and BPM's and 4-8 Ghz pickups) were actually moving - but this was tested with LVDT's mounted at various places in the ring and found not to be true. However, the measured magnetic field change only amounted to about $1 / 2$ as much as predicted by the measured orbit length change, and this is still not understood.

\section{Beam Stability}

Transverse and longitudinal beam blowups were occasionally observed - they were usually explainable by failed equipment or incorrect operating procedure. It was noted that bunching the beam with a small ARF3 voltage usually stabilized the transverse emittances (see Fig. 16). This is tentatively explained as an ion-clearing mechanism. Fig. 17 shows the transverse emittances during a typical data-taking cycle (beam current going from $40 \mathrm{~mA}$ to $10 \mathrm{~mA}$ ). It is currently believed the horizontal emittance monitor is miscalibrated by a factor of 1.5. Emittances could have easily been forced lower, however doing so did not improve the luminosity and could have developed instabilities. The damper pickup signal provided some diagnostics, and could be correlated with other beam events. Clearing electrode currents could also be correlated with beam events (turning on gas jet, emittance blowups, spikes in damper pickup signal). Catastrophic transverse emittance blowup was observed to occur if the beam was cooled too much longitudinally. At $\eta=.014, P_{\text {beam }}=5800$, and $\mathrm{I}=$ $35 \mathrm{~mA}$, the stability theshold was measured to be at approximately $\Delta P / P=4.4 \times 10^{-4}$ (FWHM). Using the Keil-Schnell inequality,

$$
\left|\frac{Z}{n}\right|<\frac{\eta E_{\text {beam }}}{I_{\text {beam }}}\left(\frac{\Delta P}{P}\right)
$$

we get a $\mathrm{Z} / \mathrm{n}$ for the Accumulator of $450 \Omega$. This includes ARF3 (350 $\Omega$ ) but not ARF1, which was shorted out. We ran typically at $15-20 \%$ above this threshold. 
1991 RUN SUMMARY

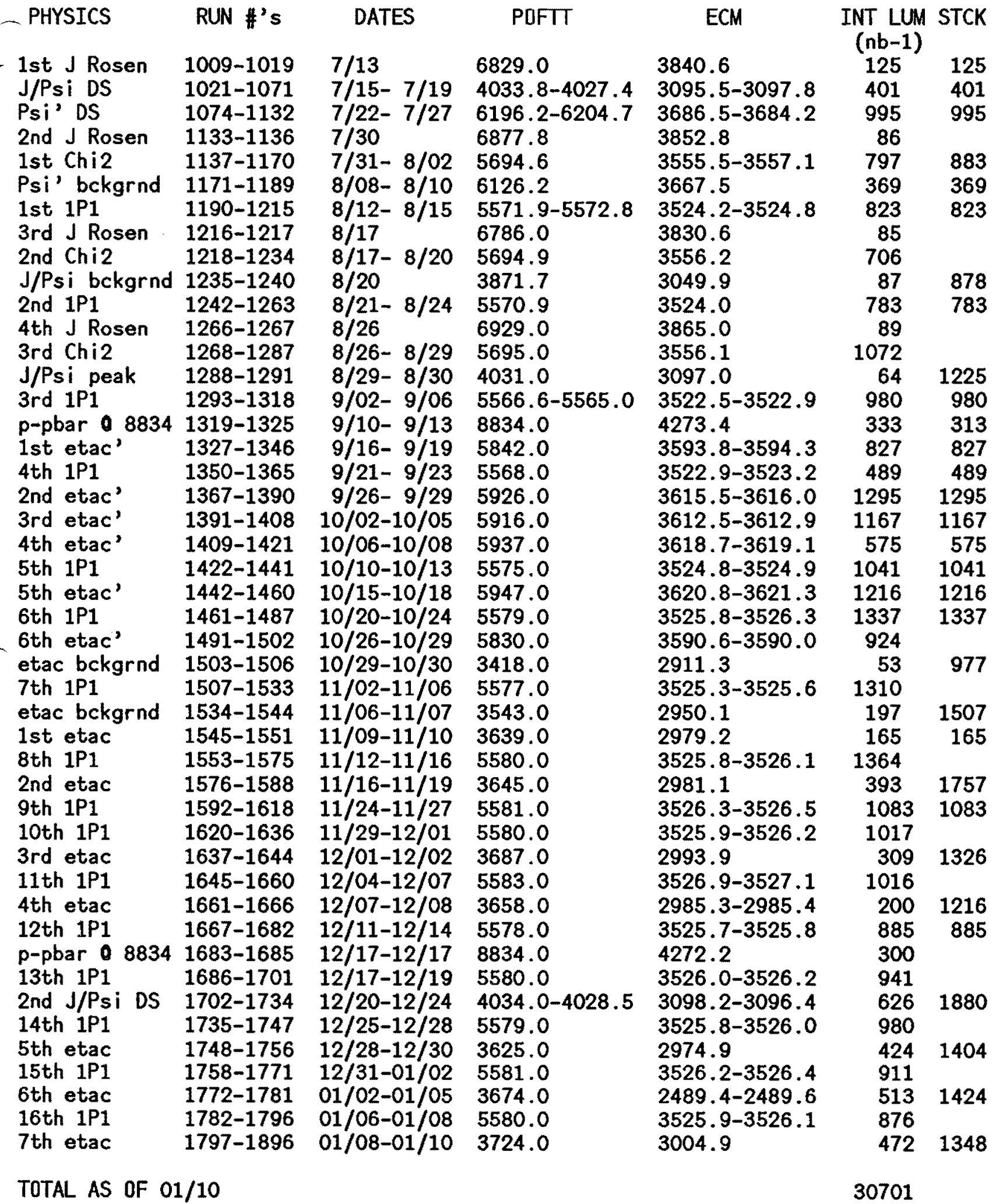

\footnotetext{
Table 1: 1991 Run summary
} 


$\begin{array}{crrr}\text { WEEK } & & \text { INT LUM (nb-1) } & \text { RUNS } \\ 1 & 6 / 30-7 / 06 & 0 & \\ 2 & 7 / 07-7 / 13 & 125 & 1009-1019 \\ 3 & 7 / 14-7 / 20 & 401 & 1021-1071 \\ 4 & 7 / 21-7 / 27 & 995 & 1074-1132 \\ 5 & 7 / 28-8 / 03 & 883 & 1133-1170 \\ 6 & 8 / 04-8 / 10 & 369 & 1171-1189 \\ 7 & 8 / 11-8 / 17 & 1057 & 1190-1222 \\ 8 & 8 / 18-8 / 24 & 1427 & 1223-1263 \\ 9 & 8 / 25-8 / 31 & 1225 & 1266-1291 \\ 10 & 9 / 01-9 / 07 & 980 & 1293-1318 \\ 11 & 9 / 08-9 / 14 & 333 & 1319-1325 \\ 12 & 9 / 15-9 / 21 & 874 & 1327-1351 \\ 13 & 9 / 22-9 / 28 & 1661 & 1352-1389 \\ 14 & 9 / 29-10 / 05 & 1243 & 1390-1408 \\ 15 & 10 / 06-10 / 12 & 1487 & 1409-1439 \\ 16 & 10 / 13-10 / 19 & 1345 & 1440-1460 \\ 17 & 10 / 20-10 / 26 & 1449 & 1461-1492 \\ 18 & 10 / 27-11 / 02 & 1010 & 1493-1510 \\ 19 & 11 / 03-11 / 09 & 1414 & 1512-1546 \\ 20 & 11 / 10-11 / 16 & 1589 & 1547-1580 \\ 21 & 11 / 17-11 / 23 & 281 & 1581-1588 \\ 22 & 11 / 24-11 / 30 & 1877 & 1592-1632 \\ 23 & 12 / 01-12 / 07 & 1691 & 1633-1664 \\ 24 & 12 / 08-12 / 14 & 942 & 1665-1682 \\ 25 & 12 / 15-12 / 21 & 1576 & 1683-1719 \\ 26 & 12 / 22-12 / 28 & 1449 & 1720-1750 \\ 27 & 12 / 29-01 / 04 & 1674 & 1751-1781 \\ 28 & 01 / 05-01 / 11 & 1348 & 1782-1805\end{array}$

Table 1: continued 1991 Run summary 

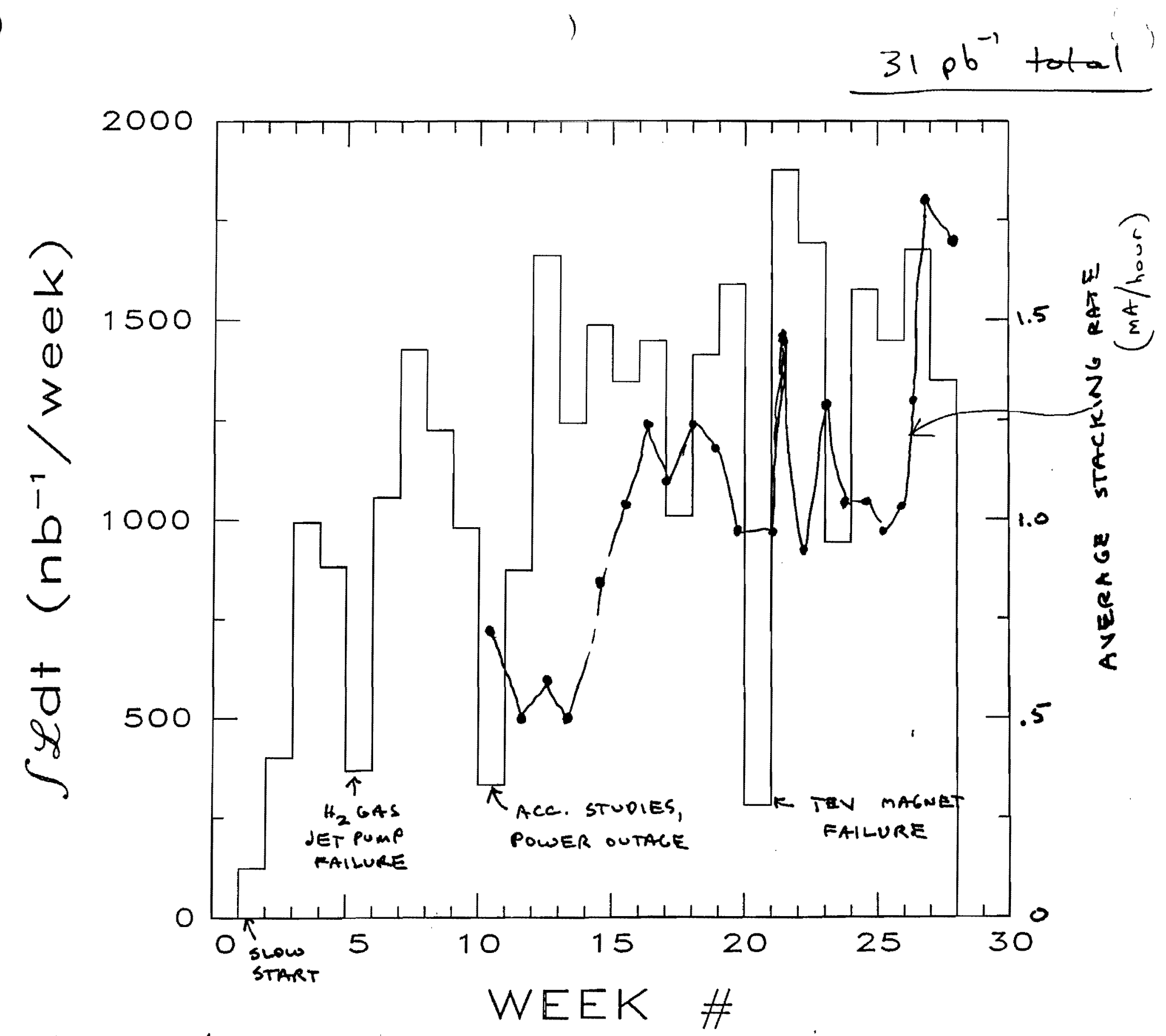

Fig. 11991 Ruminosity summary. 


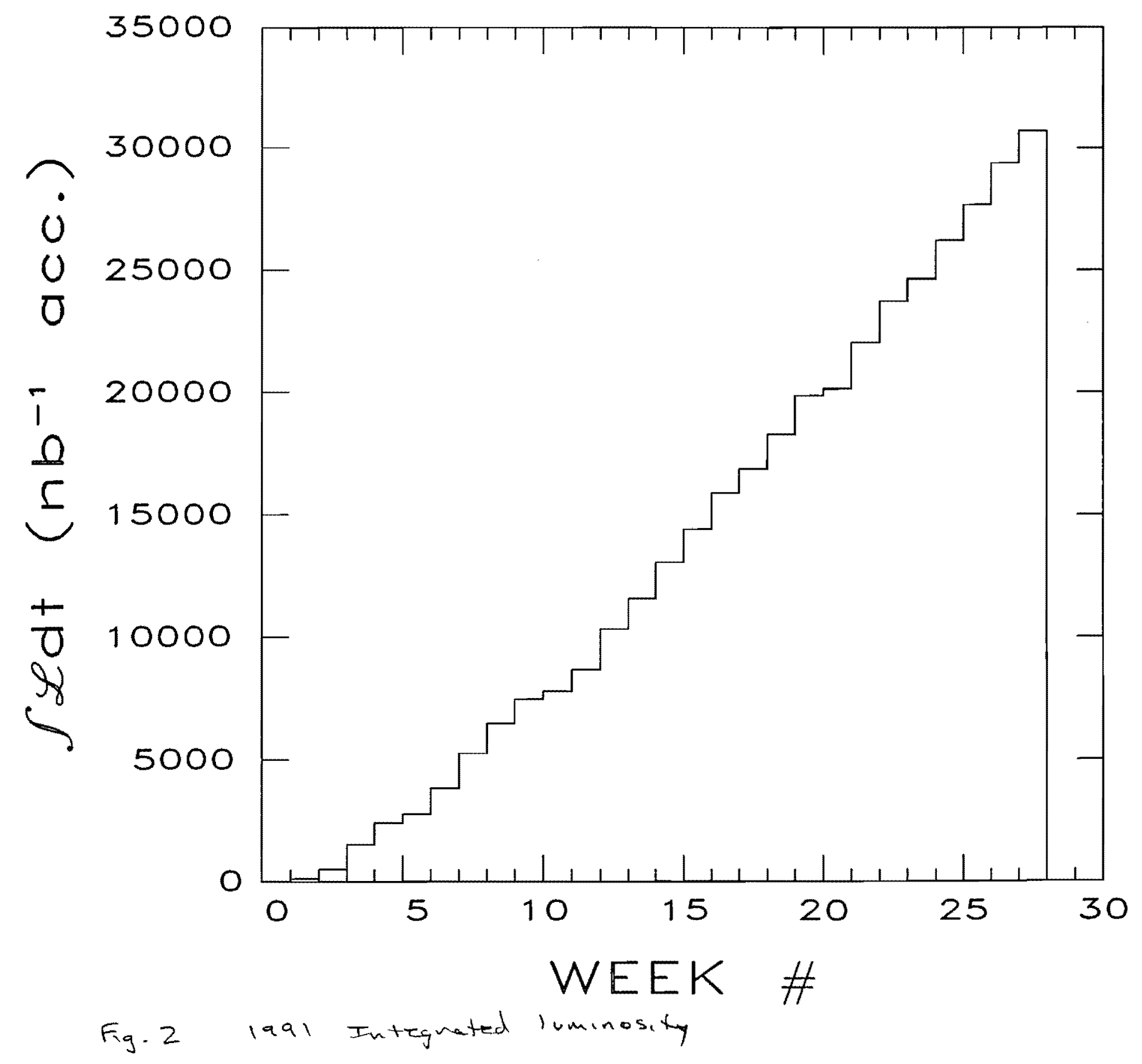


Console 14

CHS 14::

Wed 25-SEP-91

$22: 25$
3600

$Y=A: I B E A M \quad M A$ A: R3HLFB VOLT

24

1600

$\leqslant 1$

HZ.

$H Z$.

12

800

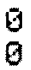

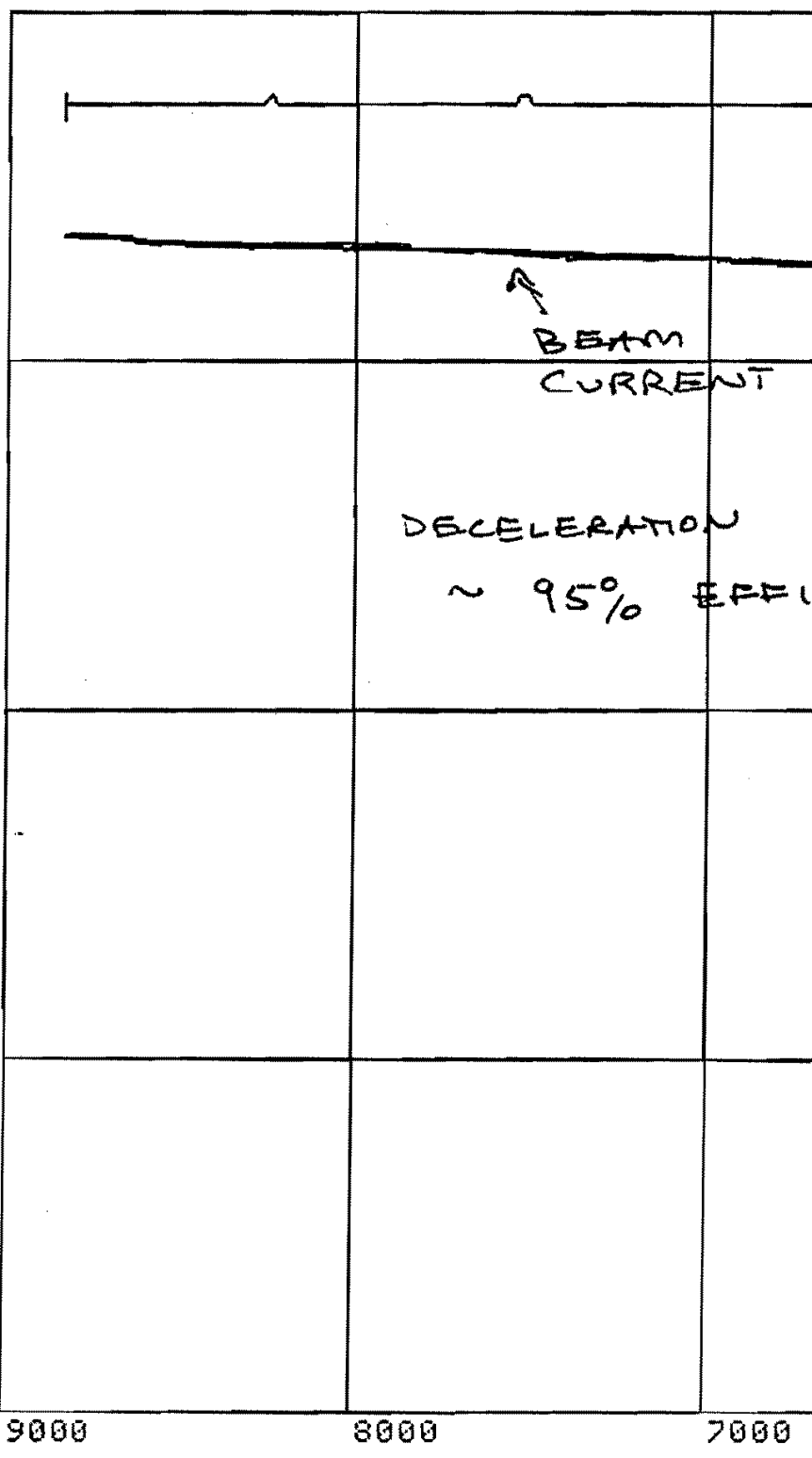

( 1 HZ.) $X=X: F O F T T \quad \hat{H} / D$ HEVP

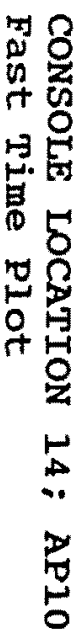

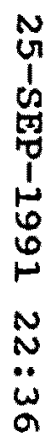

Fig. 3

Deceleration for 2nd $\eta_{c}^{\prime}$ point 
48

1500

जin?

32

1290

$\frac{10}{5}$

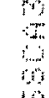

s.

tr.

告

0
$\frac{1}{2}$
0
0
0
0
0
0

$\stackrel{I}{\Xi}$

壱
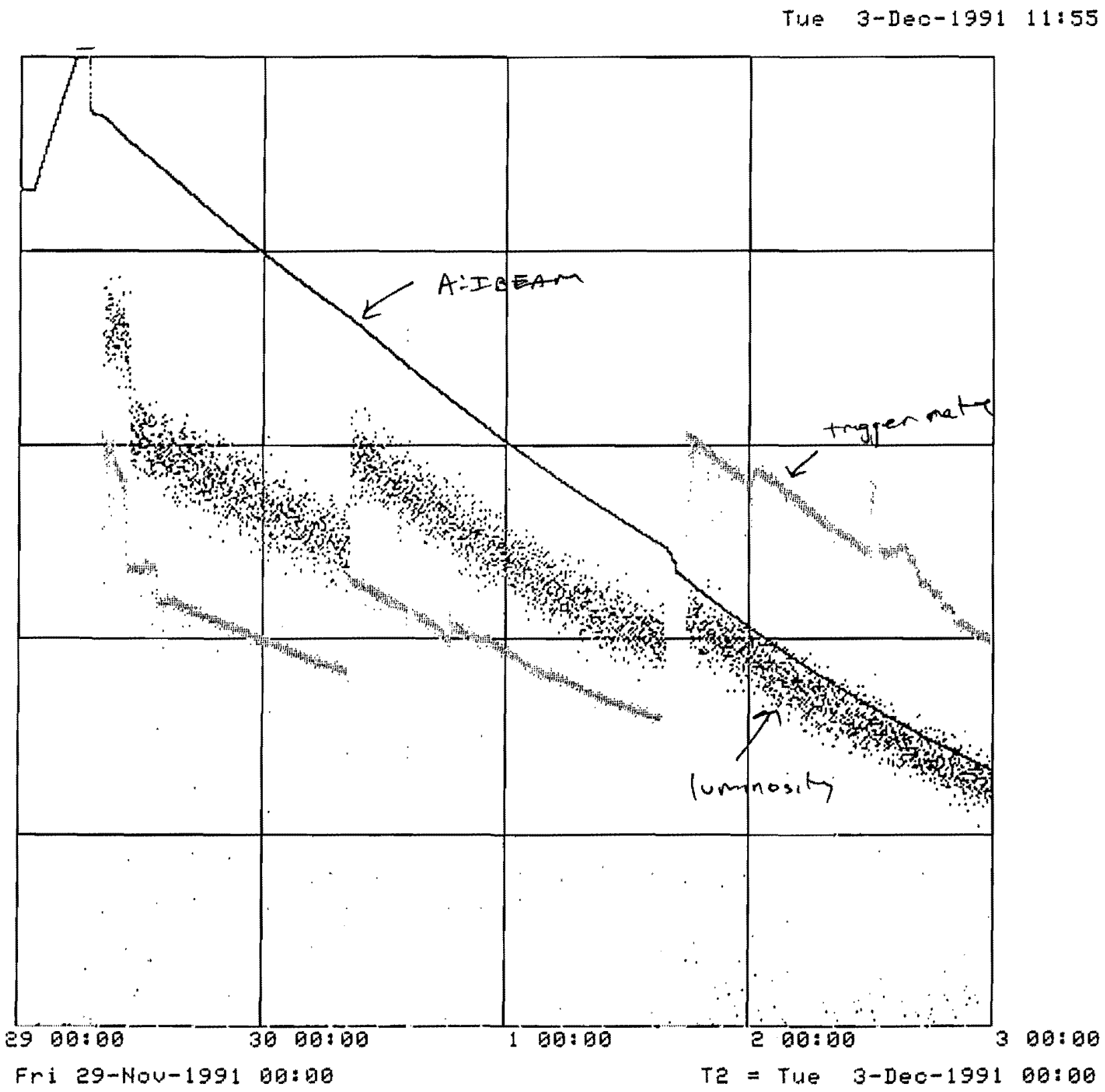

Fig. 4. Typical datartatung ayde 


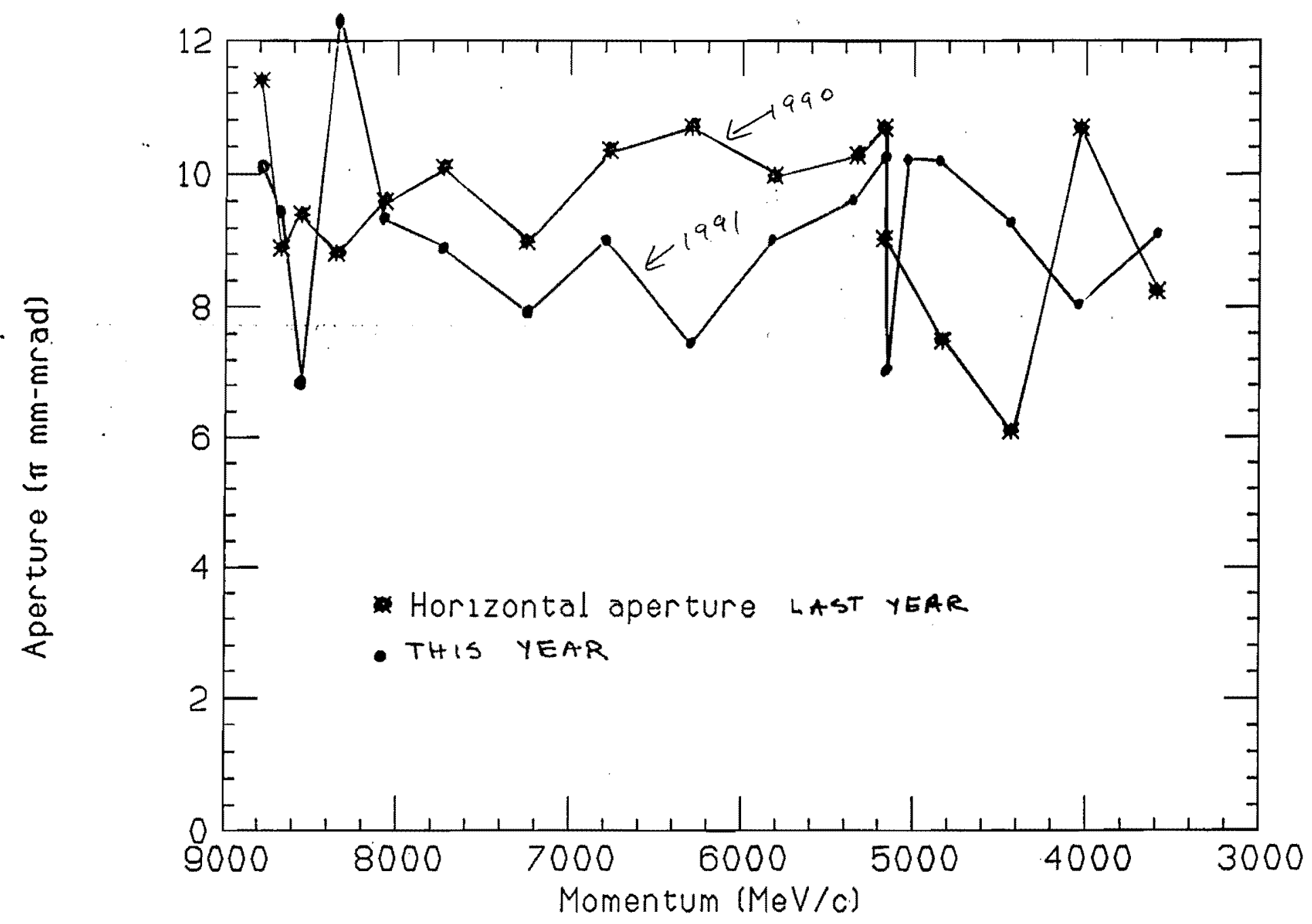

Fig ya) Horizontal aperture vS. momentum 


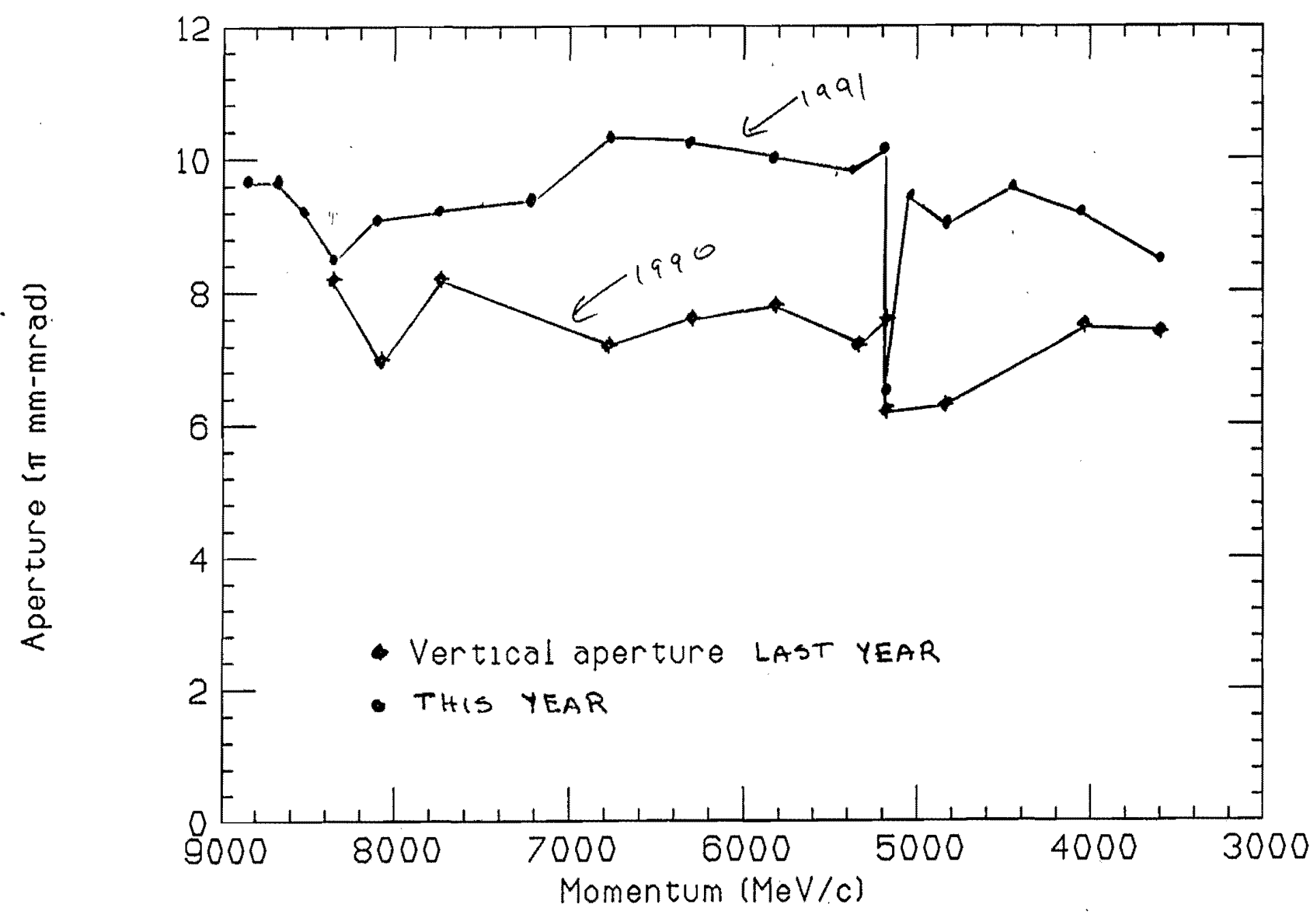

Fig. $4 b$ Vertical aperture vs. momentum. 



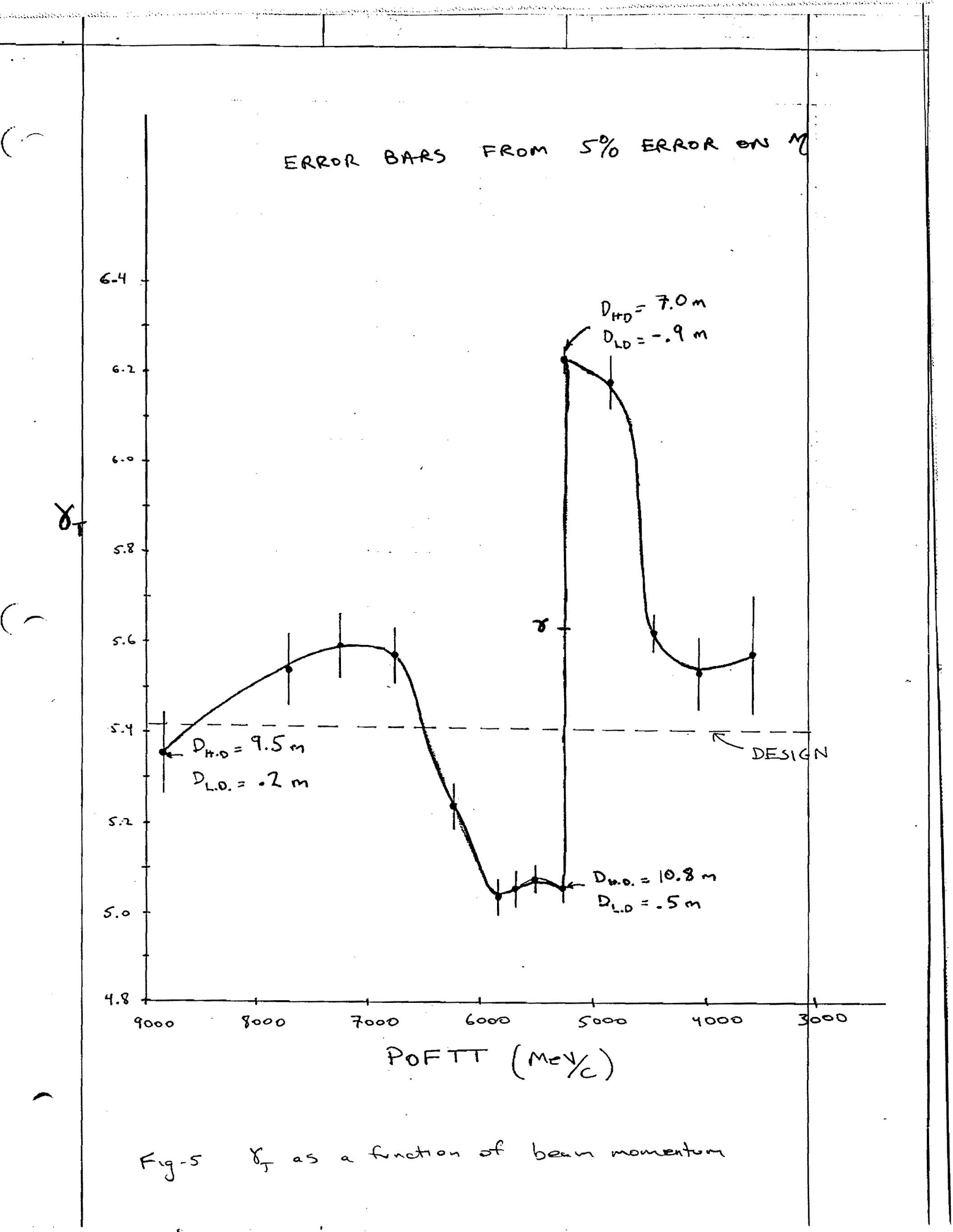




\section{)}

CONSOLE LOCATION 17, MCR-W2 deceleration from 5580 to 3645

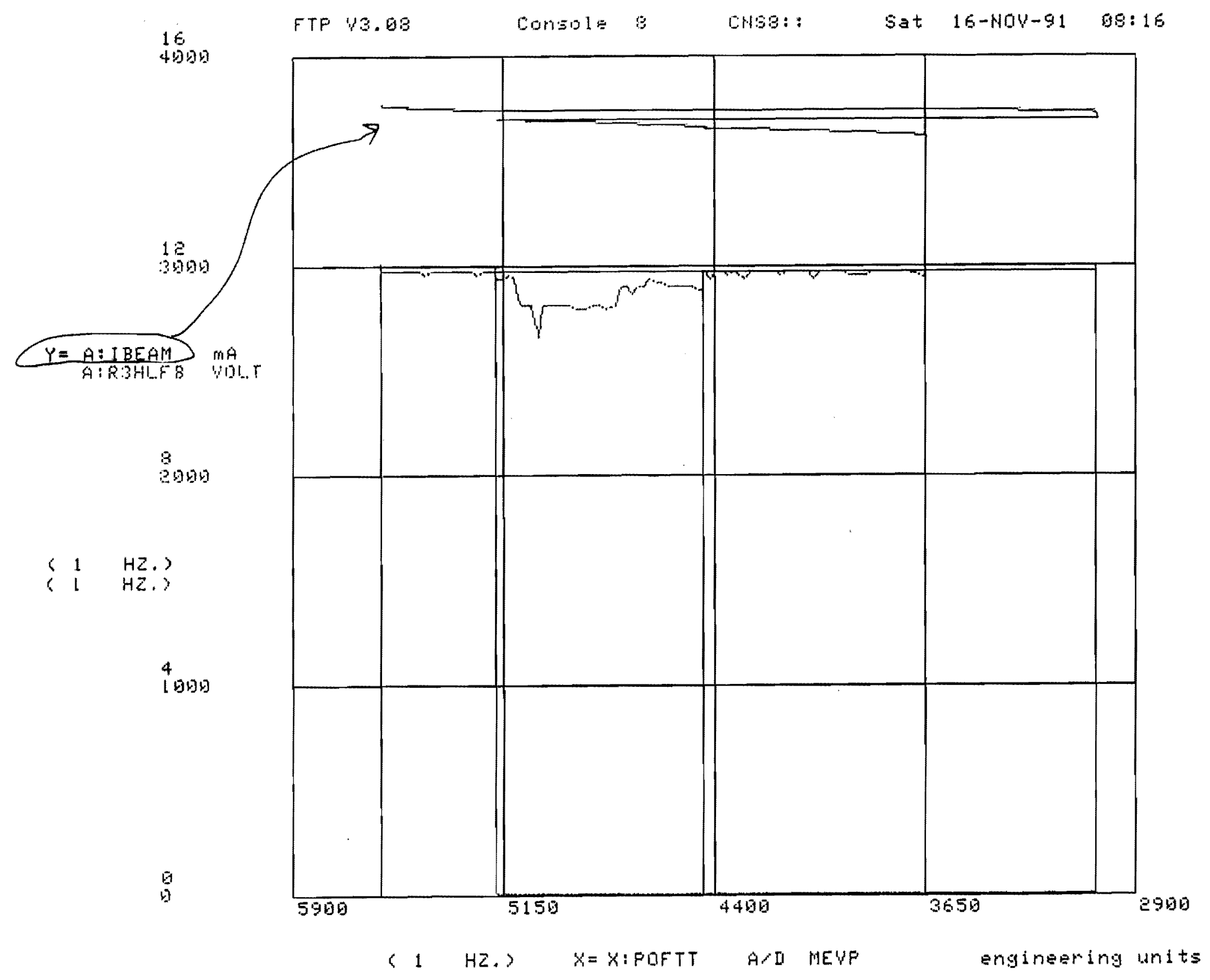

Fig. 6 Thansition crossing efficiency and below transition develeration
efficiency. 


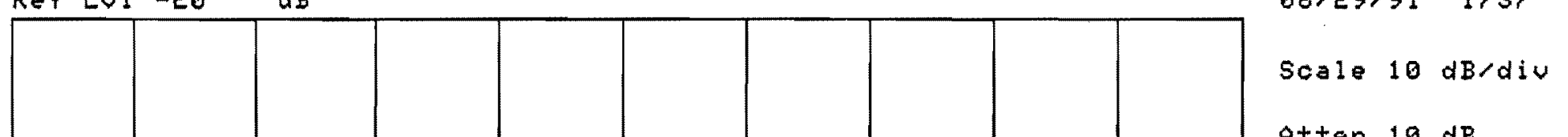

Atten $10 \mathrm{dE}$

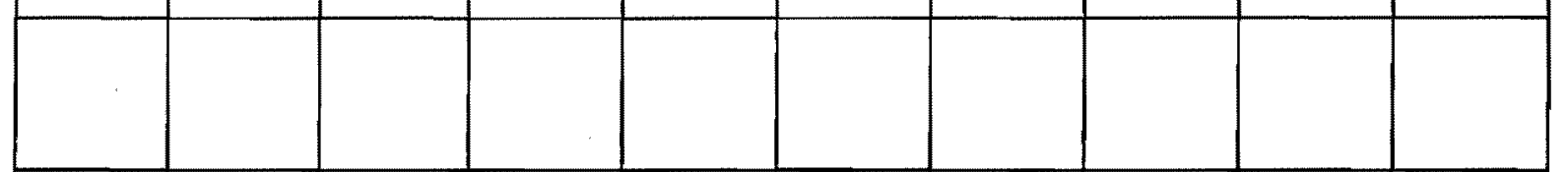

Swp 10 sec

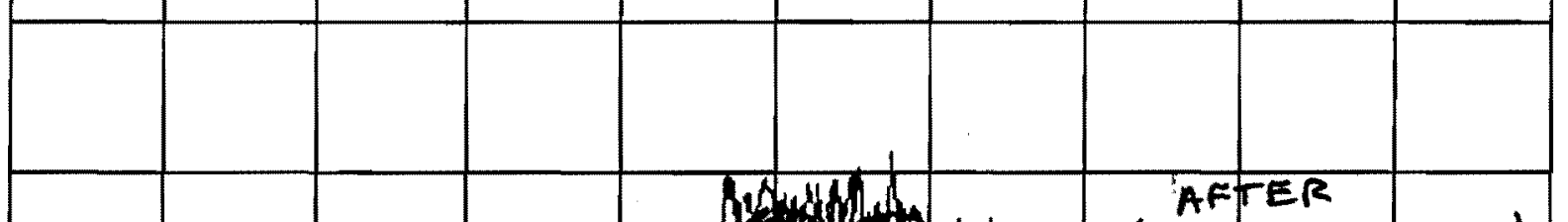

Vid BW $10 \mathrm{~Hz}$

Res BW $100 \mathrm{~Hz}$
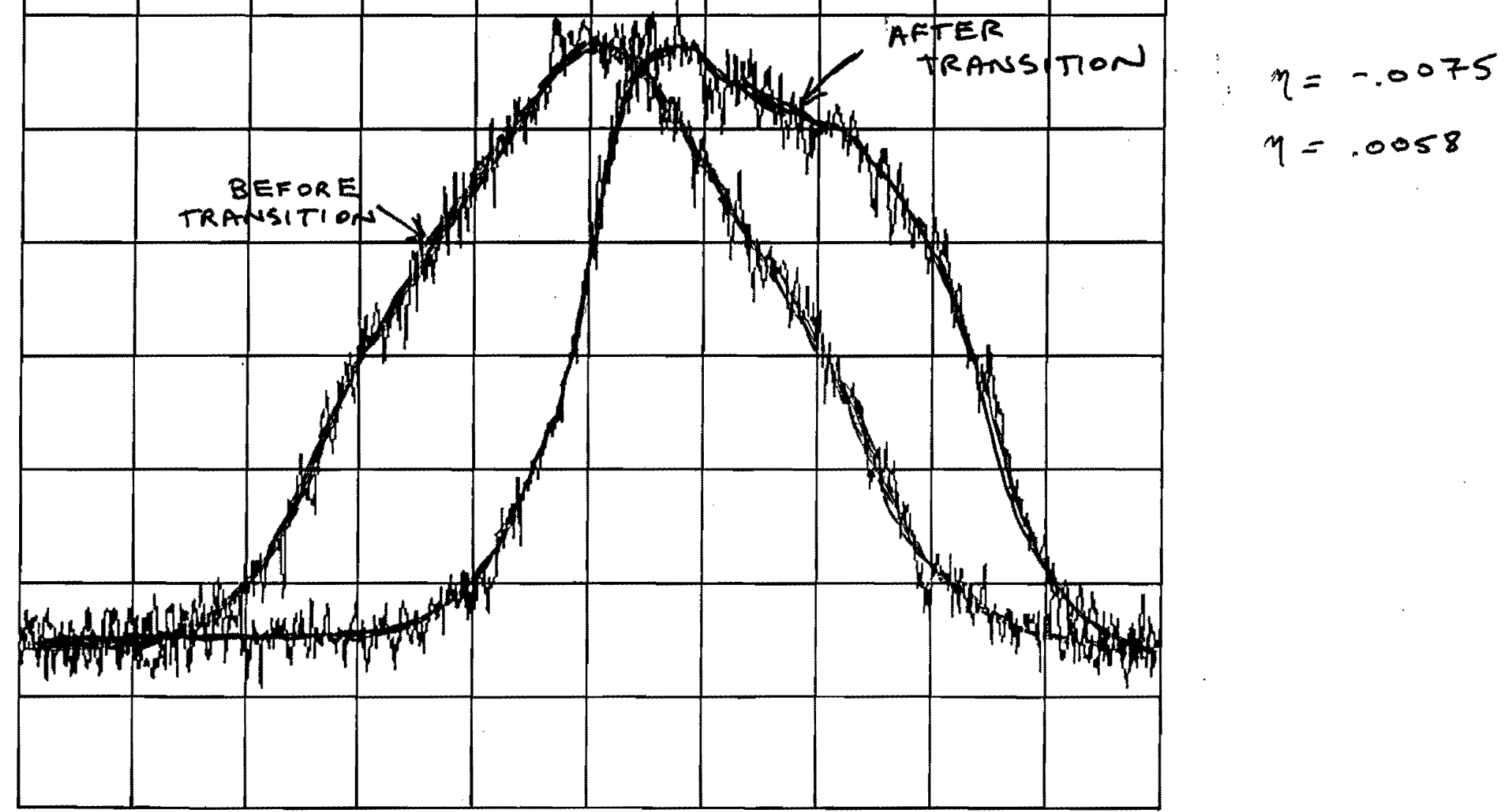

Start Freq $79.03829001 \mathrm{MHz}$

Stop Freq $79.04329001 \mathrm{MHz}$

F.g.7. Longitudenal Schottter before and after transition crossing 


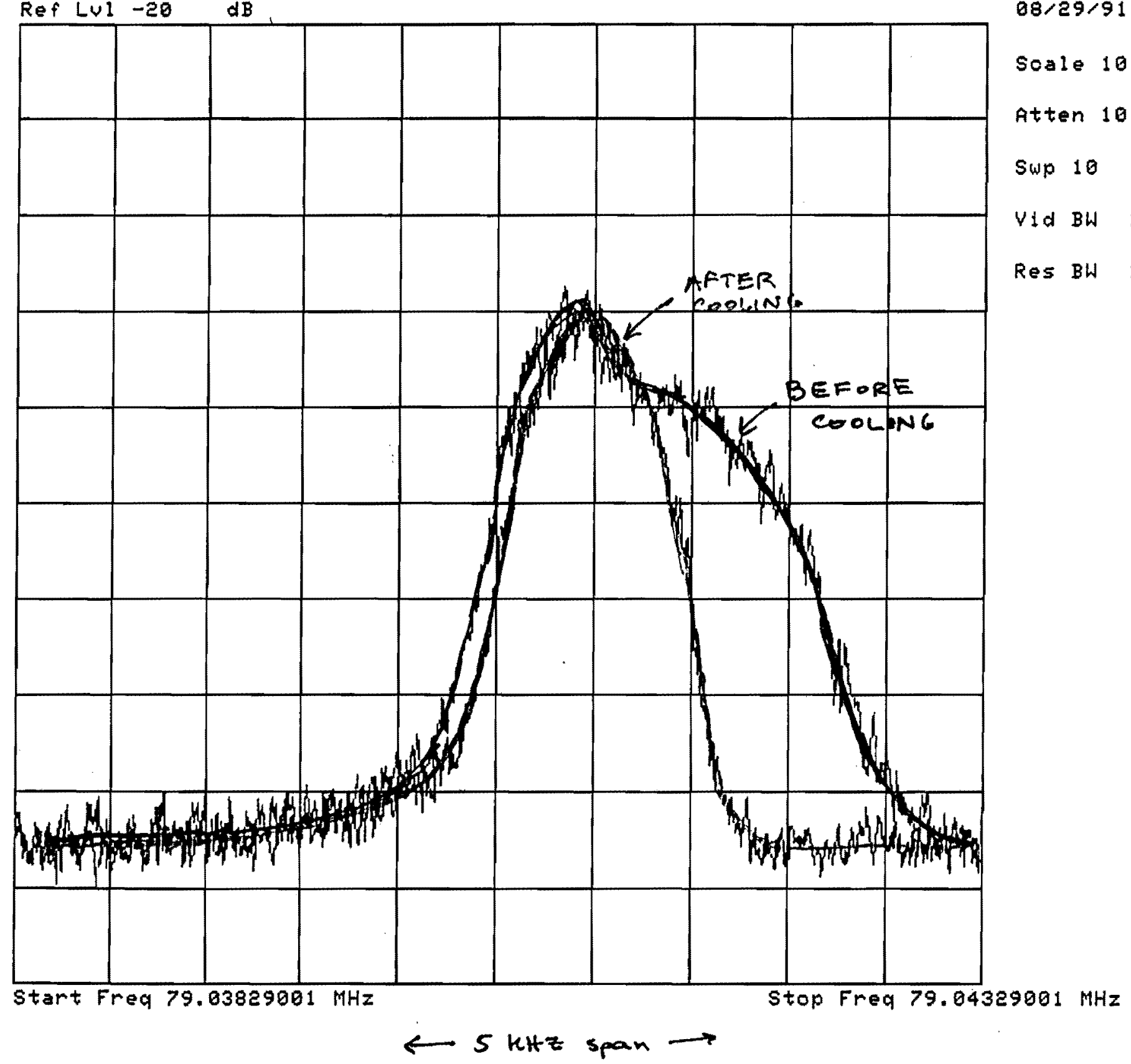

Fg. 8. cooling below transtion 
ACCUMULATOR PRESSURE PROFILE $01 / 99 / 92 \quad 1821$ $1.0 E-B 7$ AVERAGE PRESSURE (ION PUMPS) $=1.828 E-68$ (ION GAUGES) $=3.0662 E-09$

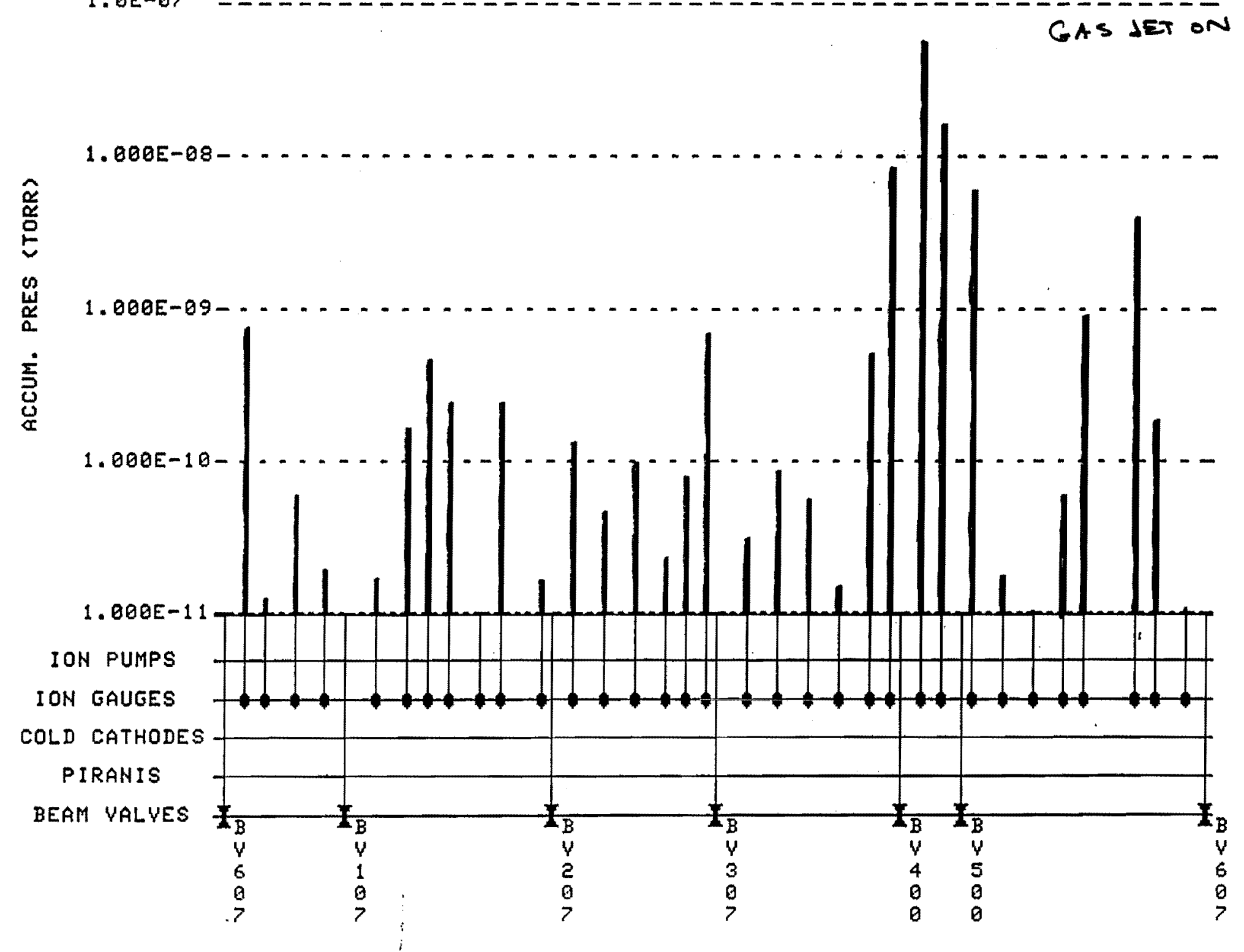

0
1
$c$
0
1
1
0
0
$N$
$\omega$
0
$\ddot{N}$
$N$

Fig 9: Acc. Vacuom 
$29.6 \mathrm{~mA}$, jet off ' after stacking for $M_{c}^{\prime}$ ACCUMULATOR PRESSURE PROFILE $09 / 16 / 911028$ 1.0E-O) AVERAGE PRESSURE (ION PUMPS) $=1.383 E-08$ (ION GAUGES $2=\frac{3.984 E-10}{\text { GAS JET OFF }}$

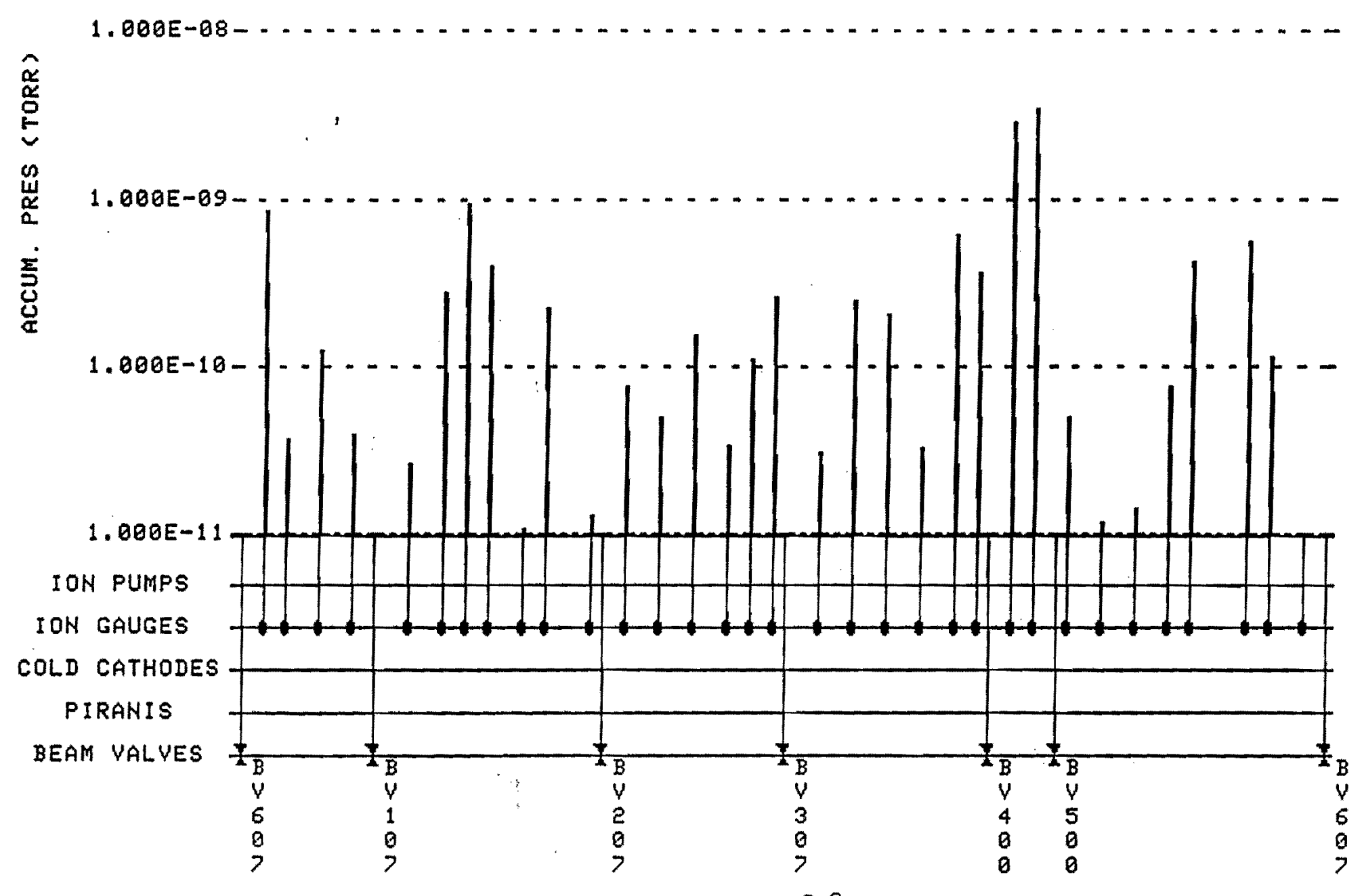

Fig w. Ace. Vacuum, Gas jet off 


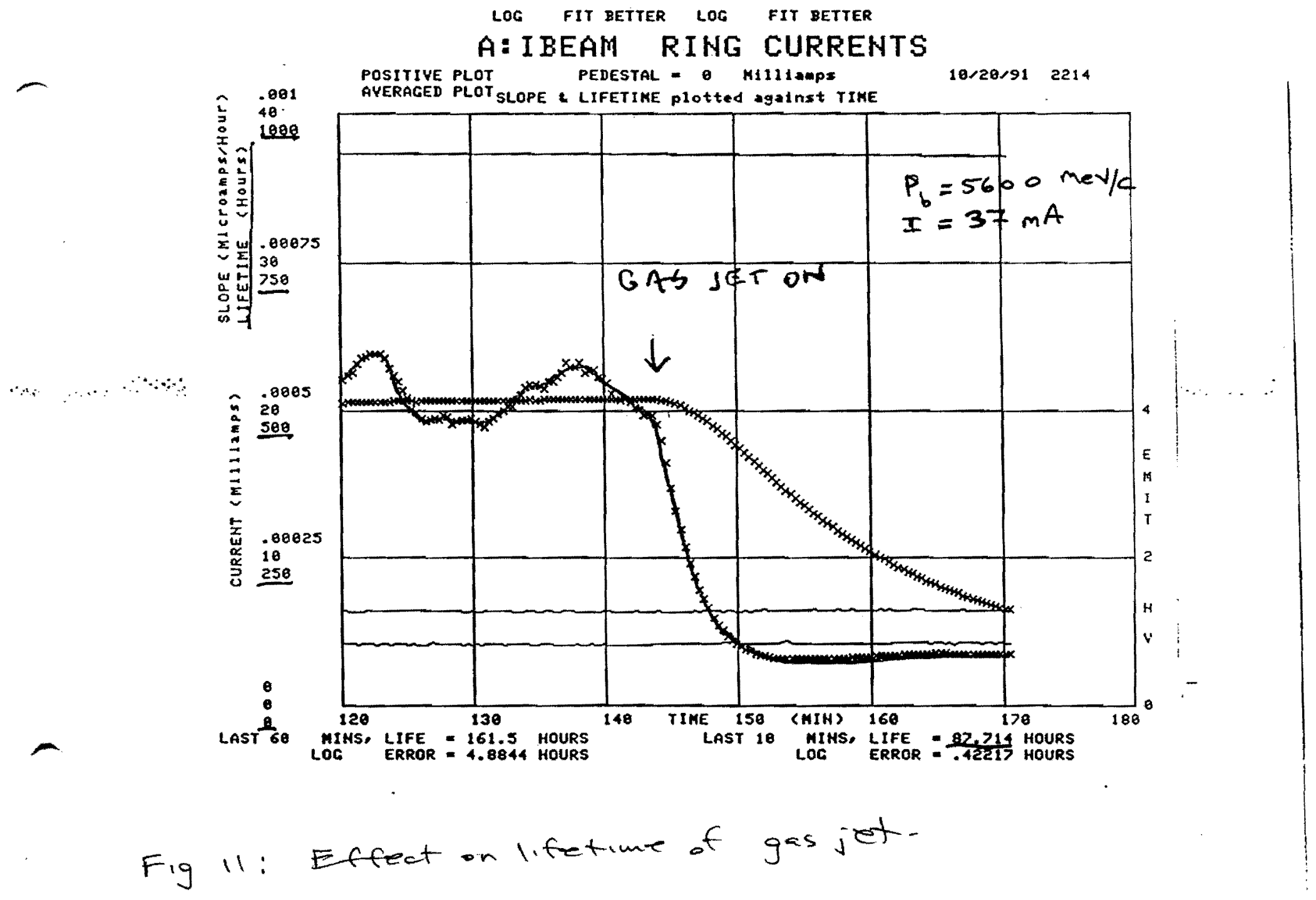


COT JLE LOCATION 43 ,

11-OCT-1991 00:43

Lunuerjack Plot MCR A:BFIELD

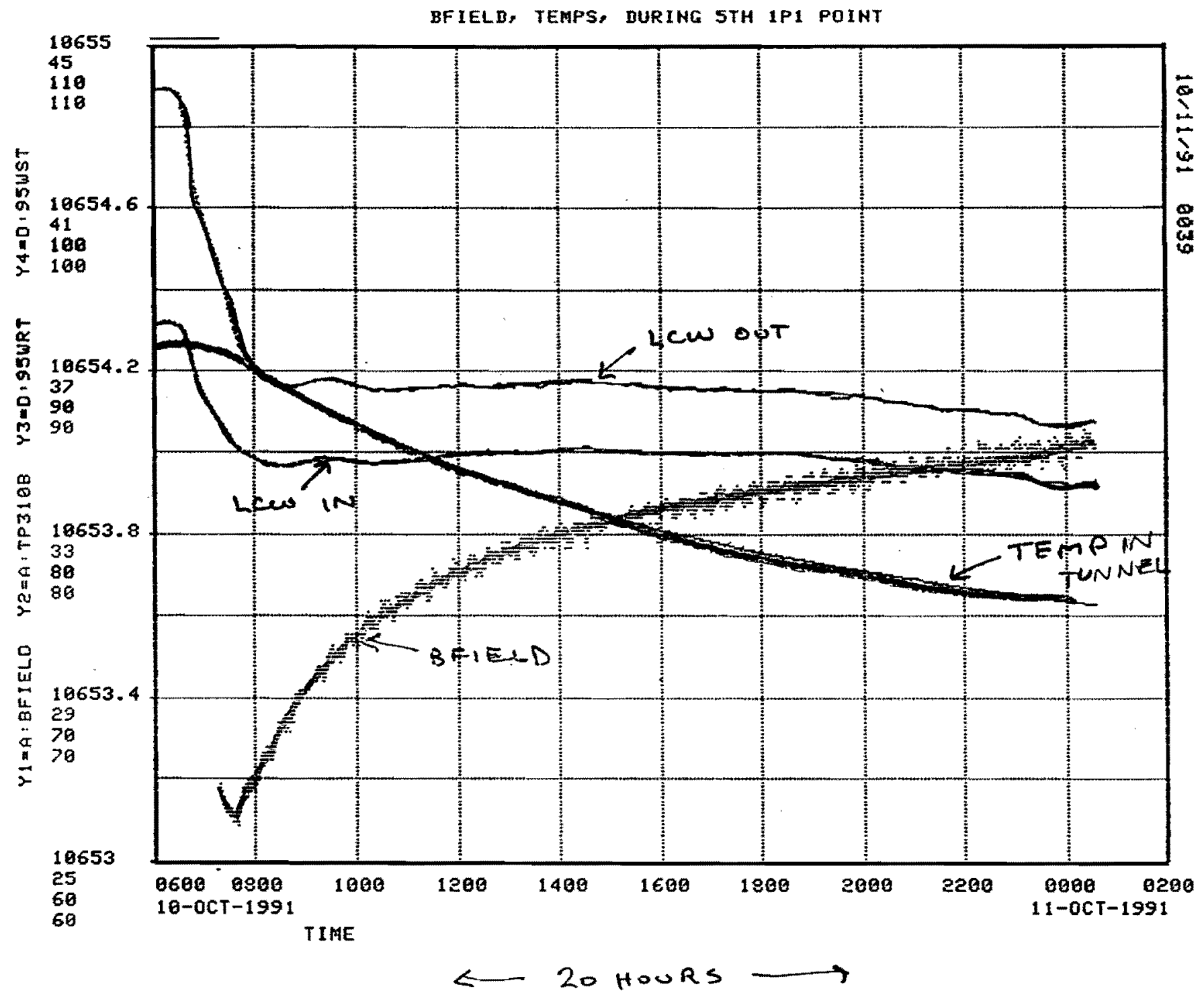

Fig. 13 Temperature and Bfield vs. tume 
CO OLE LOCATION 43 ,

12-OCT-1991 18:03

mi_- during 5 th $1 \mathrm{p} 1$

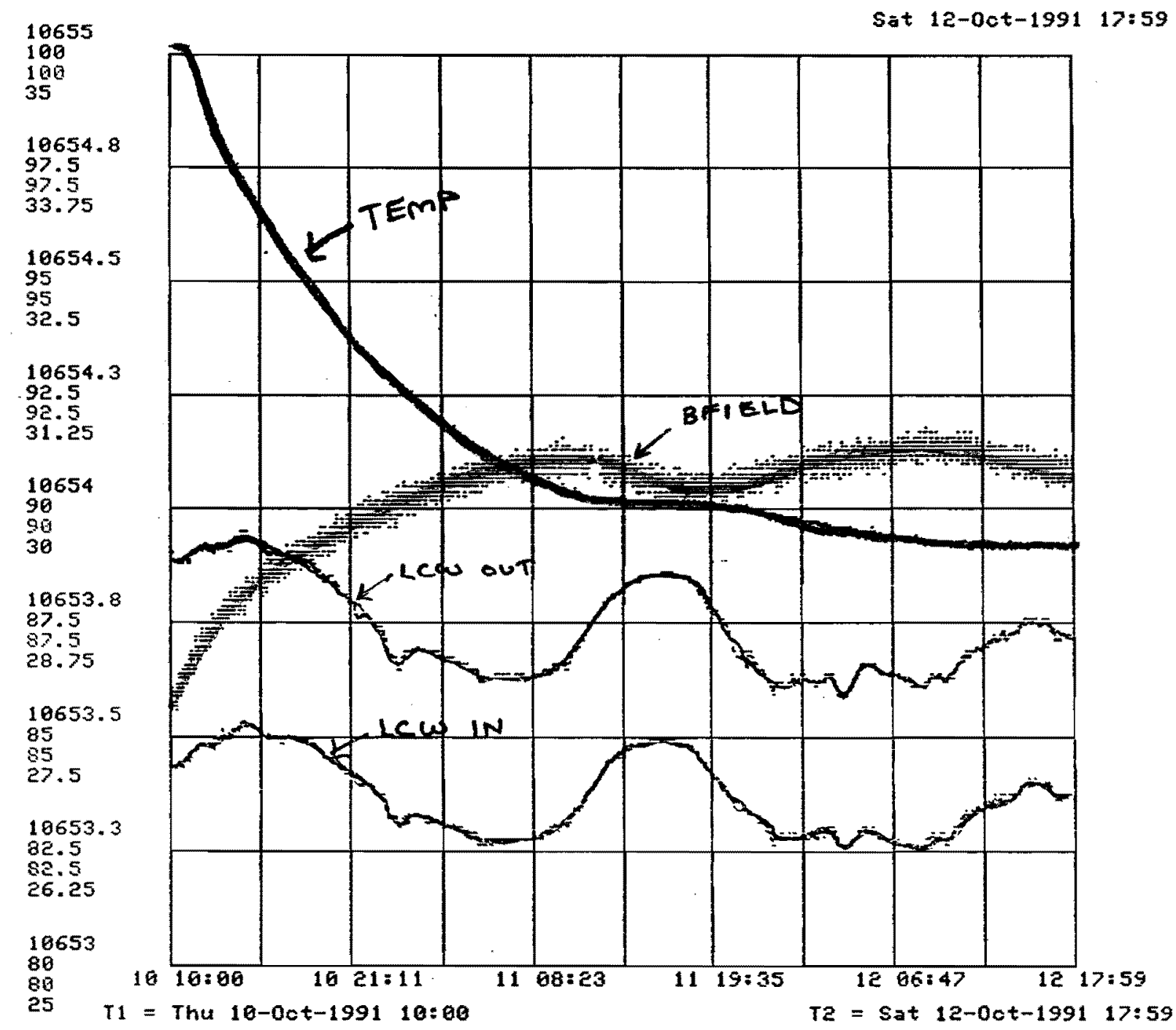

$\longleftrightarrow$ 56 HOURS $\longrightarrow$

$$
\begin{aligned}
& \triangle T E M P=6^{\circ} \mathrm{C} \\
& \triangle L C W=20^{\circ} \mathrm{F} \\
& \triangle B=1 \text { GAUSS }
\end{aligned}
$$

Fig 14 Temperature and B field vs. time. 


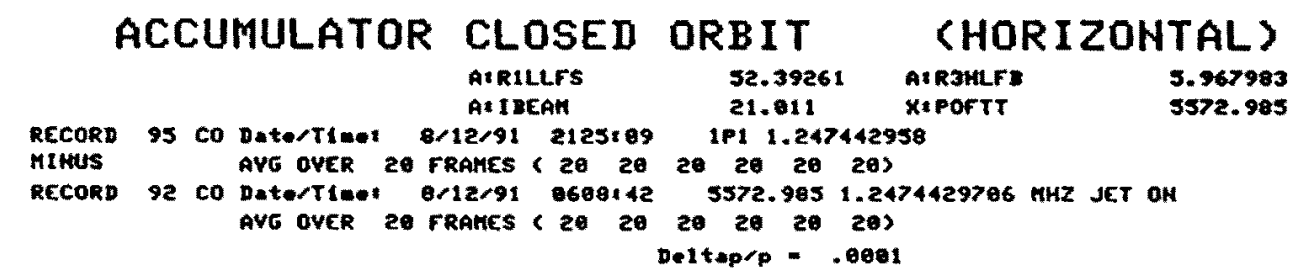

BEAT POSITIONS (mm)

\begin{tabular}{|ll} 
A101 & -1 \\
A103 & -.09 \\
A104 & 0 \\
A106 & -08 \\
A106 & 0 \\
A1010 & -28 \\
A1011 & 1.91 \\
A1014 & 1
\end{tabular}

$\begin{array}{ll}\text { A2014 } & 1.43 \\ \text { A2011 } & .93 \\ \text { A2018 } & 1.02 \\ \text { A208 } & 6 \\ \text { A206 } & .25 \\ \text { A204 } & 0 \\ \text { A203 } & 6 \\ \text { A201 } & 0\end{array}$

$\begin{array}{ll}\text { A301 } & 0 \\ \text { A303 } & 0 \\ \text { A304 } & .09 \\ \text { A306 } & .18 \\ \text { A306 } & -.09 \\ \text { A3010 } & .81 \\ \text { A3011 } & 1.65 \\ \text { A3014 } & 1.51\end{array}$

$\begin{array}{ll}\text { A4014 } & 1.23 \\ \text { A4011 } & : 92 \\ \text { A4010 } & 1.11 \\ \text { A408 } & -.69 \\ \text { A406 } & .27 \\ \text { A404 } & 0 \\ \text { A403 } & -.69 \\ \text { A401 } & -.11\end{array}$

$\begin{array}{ll}\text { ASQ1 } & 0 \\ \text { A503 } & -0.97 \\ \text { A504 } & 0 \\ \text { A506 } & : 3 \\ \text { A508 } & 0 \\ \text { A5010 } & -53 \\ \text { A5011 } & 1.23 \\ \text { A5014 } & 1.29\end{array}$

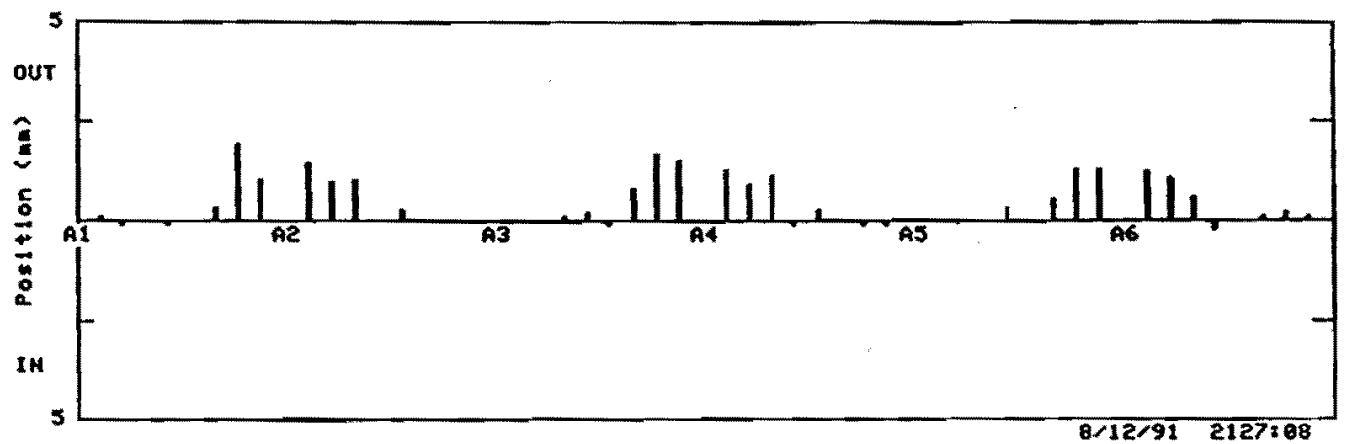

TYPICALLY $\frac{d L}{L}$ measured PREDICTED A $\frac{d B}{B}$. TWICE AS LARGE AS $\frac{d B}{B}$ measored ???

$$
\begin{aligned}
& \frac{d P}{P}=\gamma_{T}^{2} \frac{d L}{L}+\frac{d B}{B} \\
& \frac{d P}{P}=\gamma^{2} \frac{d F}{F}+\gamma^{2} \frac{d L}{L} \\
& \frac{d B}{B}=\gamma_{T}^{2} \frac{d F}{F}+\frac{\gamma^{2}-r_{T}^{2}}{\gamma^{2}} \frac{d P}{P} \\
& \frac{d B}{B}=\gamma^{2} \frac{d F}{F}+\left(\gamma^{2}-\gamma_{T}^{2}\right) \frac{d L}{L}
\end{aligned}
$$

Fig 15: Dobit length change temperature drift. 
Prior to the BPM platen we wo r having difficulty cooling the beam transversely at the start of the BPM plateau both horizontal and vertical remittances started to drop and the bean lifetime increased dramatically It ap that a small amount of RE helps the stochastic cooling process.

LOG FIT BETTER LOG FIT BETTER

A: IBEAM RING CURRENTS

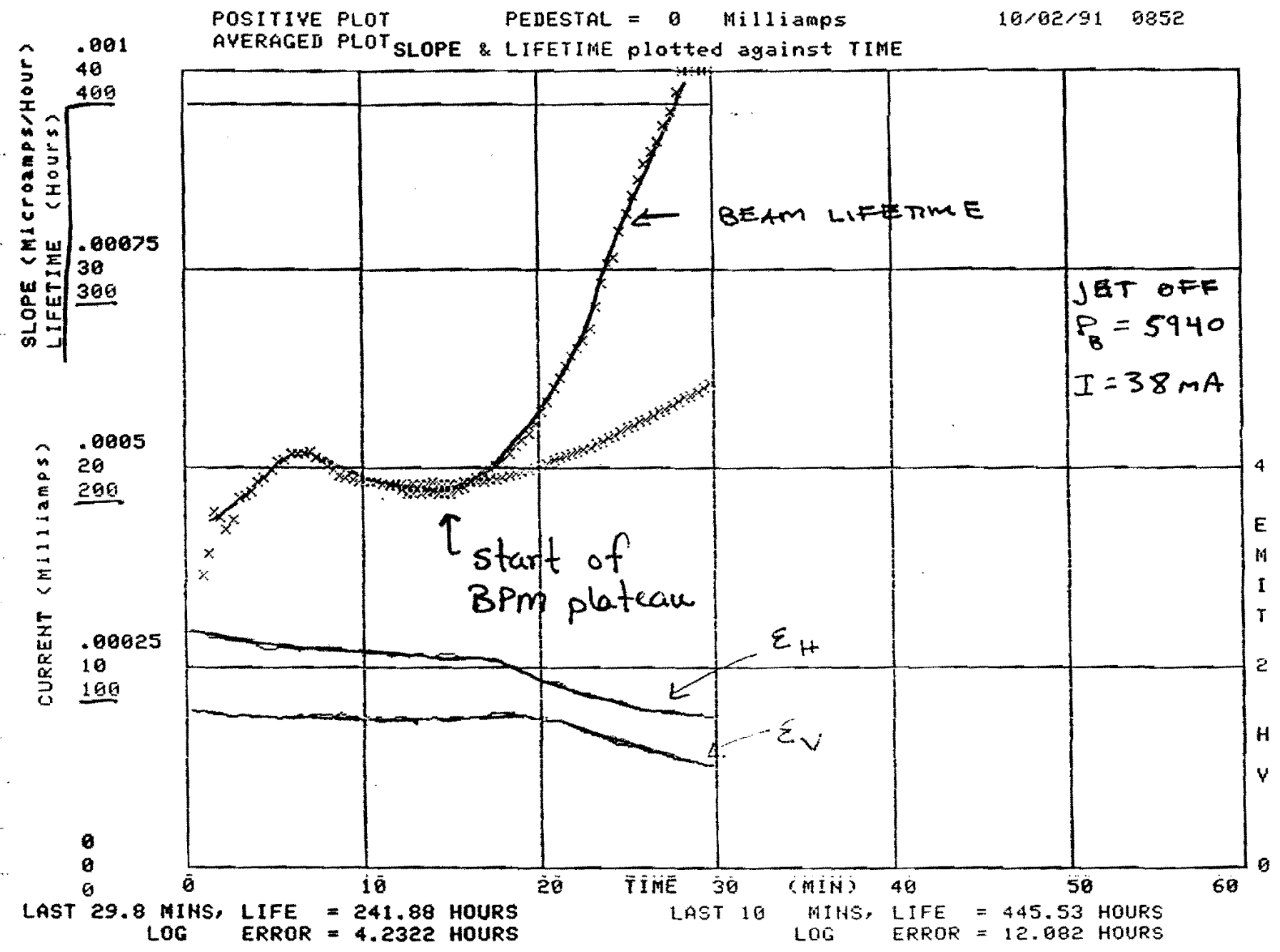

ION CLEARING ??

Fig. th Effect of bunching beam on transverse emittance 0925 Adjusted $486 \mathrm{GH}$ op /p pick ap position by equalizing the notch frequency and the average longitudinal schoftly frequency.

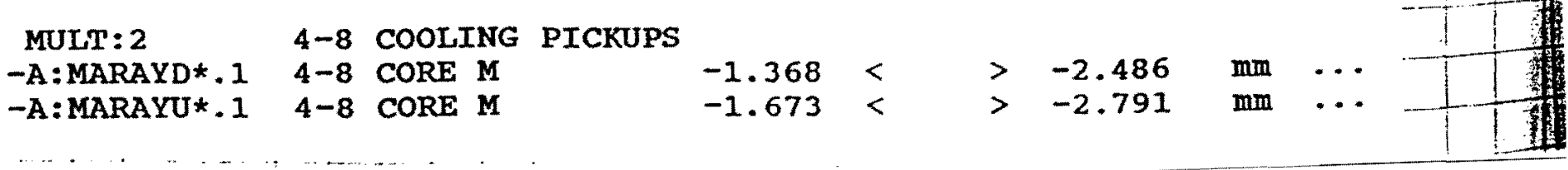


EMITTANCES For GTH IPI

The 24-0ot-1391 15:17

$\therefore$

3.2

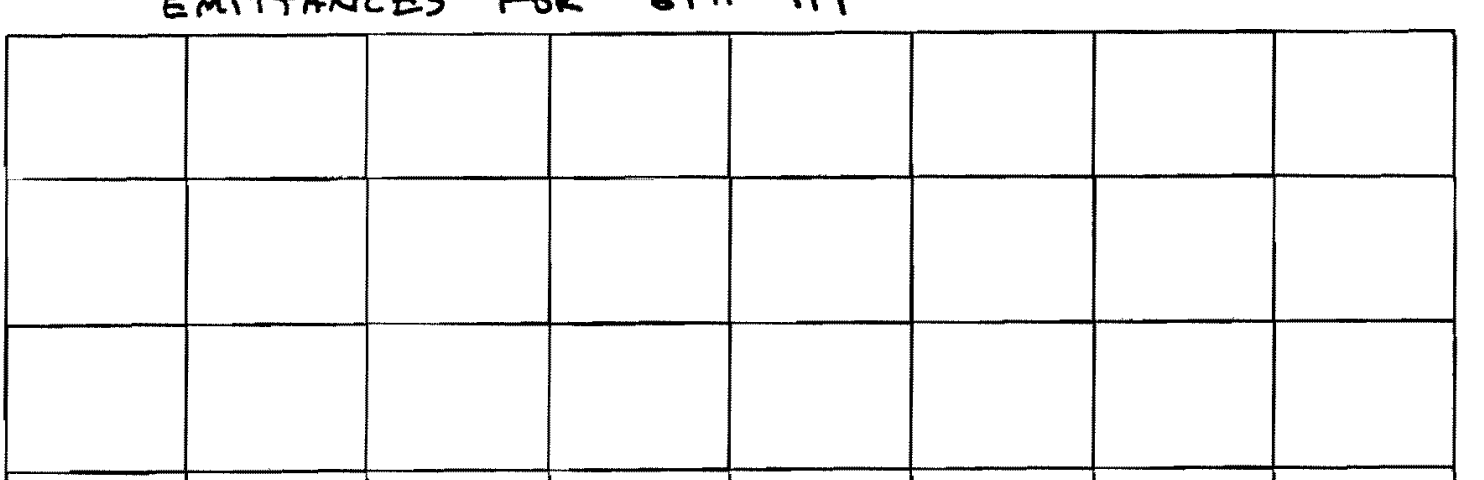

$6 \quad 2.4$

I

$\stackrel{\Phi}{s}$

1.6

II

岕

$\ddot{a}$

.8

$\stackrel{I}{E}$

폴

3

$2015: 90$

$T 1=\operatorname{sun} 20-00 t-1901$ 1E: 00

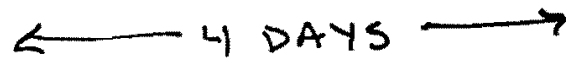

Fig-17. Typical transwerse emittance during datatating 